\title{
Therapeutic interventions to reduce the risk of progression from prediabetes to type 2 diabetes mellitus
}

This article was published in the following Dove Press journal:

Therapeutics and Clinical Risk Management

20 March 2014

Number of times this article has been viewed

\author{
Katia Cristina Portero \\ McLellan' \\ Kathleen Wyne 2 \\ Evangelina Trejo Villagomez ${ }^{2}$ \\ Willa A Hsueh ${ }^{2}$ \\ 'Department of Public Health, \\ School of Medicine, Sao Paulo State \\ University, Botucatu, SP, Brazil; \\ ${ }^{2}$ Division of Diabetes, Obesity and \\ Lipids, Department of Medicine, The \\ Methodist Hospital Diabetes and \\ Metabolism Institute, and the Houston \\ Methodist Research Institute, Weil \\ Cornell Medical College, Houston, \\ TX, USA
}

\begin{abstract}
Clinical trials have demonstrated that it is possible to prevent diabetes through lifestyle modification, pharmacological intervention, and surgery. This review aims to summarize the effectiveness of these various therapeutic interventions in reducing the risk of progression of prediabetes to diabetes, and address the challenges to implement a diabetes prevention program at a community level. Strategies focusing on intensive lifestyle changes are not only efficient but cost-effective and/or cost-saving. Indeed, lifestyle intervention in people at high risk for type 2 diabetes mellitus (T2DM) has been successful in achieving sustained behavioral changes and a reduction in diabetes incidence even after the counseling is stopped. Although prediabetes is associated with health and economic burdens, it has not been adequately addressed by interventions or regulatory agencies in terms of prevention or disease management. Lifestyle intervention strategies to prevent T2DM should be distinct for different populations around the globe and should emphasize sex, age, ethnicity, and cultural and geographical considerations to be feasible and to promote better compliance. The translation of diabetes prevention research at a population level, especially finding the most effective methods of preventing T2DM in various societies and cultural settings remains challenging, but must be accomplished to stop this worldwide epidemic.
\end{abstract}

Keywords: lifestyle, T2DM, intervention, prevention

\section{Introduction}

The prevalence and the incidence of type 2 diabetes mellitus (T2DM) has rapidly increased over the past several decades and is now attaining epidemic proportions worldwide, paralleling the increase in obesity prevalence, particularly in developing countries. ${ }^{1-4}$ T2DM is increasing most rapidly in the People's Republic of China, India, and the Middle East, ${ }^{1,2}$ but is also rising in low- and middle-income countries around the world, as well as in North America and Europe. ${ }^{3,4}$ Moreover, the global prevalence of diabetes is estimated to rise from 382 million to 592 million by $2035 .{ }^{4}$ Recent analysis of the economic impact of diabetes in the US has demonstrated that in 2012 the estimated total economic cost of the disease was US\$245 billion, a 41\% increase from the previous estimate of US\$174 billion in 2007.5

Prediabetes is defined as a state of abnormal glucose homeostasis characterized by impaired fasting glucose (IFG), impaired glucose tolerance (IGT), or both (Table 1). ${ }^{6,7}$ Plasma glucose levels in this range increase the risk of developing frank diabetes, defined as fasting glucose level $\geq 126 \mathrm{mg} / \mathrm{dL}$ or 2 -hour prandial glucose $\geq 200 \mathrm{mg} / \mathrm{dL}{ }^{8}$
Correspondence: Willa A Hsueh 6670 Bertner Ave R8-III,

Houston, TX 77030, USA

Tel + I $71344 \mid 2520$

$\mathrm{Fax}+17134412178$

Email wahsueh@tmhs.org 
Table I Classification of glucose tolerance states

\begin{tabular}{lll}
\hline $\begin{array}{l}\text { Glucose } \\
\text { tolerance } \\
\text { states }\end{array}$ & $\begin{array}{l}\text { Fasting } \\
\text { plasma glucose } \\
\text { level }(\mathbf{m g} / \mathbf{d L})\end{array}$ & $\begin{array}{l}\text { 2-hour plasma glucose } \\
\text { after a } 75 \text { g glucose } \\
\text { load on OGTT }(\mathbf{m g} / \mathbf{d L})\end{array}$ \\
\hline IFG & $100-125$ & $<200$ \\
Isolated IFG & $100-125$ & $<140$ \\
IGT & $<126$ & $140-199$ \\
Isolated IGT & $<100$ & $140-199$ \\
Combined IFG/IGT & $100-125$ & $140-199$ \\
NGT & $<100$ & $<140$
\end{tabular}

Note: Data from Nathan et al. ${ }^{7}$

Abbreviations: IFG, impaired fasting glucose; IGT, impaired glucose tolerance; NGT, normal glucose tolerance; OGTT, oral glucose tolerance test.

\section{Prediabetes is a disease}

Microvascular and macrovascular damage starts during prediabetes and is associated with an increased risk of cardiovascular disease early in the progression to T2DM. ${ }^{9}$ Elevated glucose levels damage endothelial cells, which can lead to microvascular disease. ${ }^{10}$ Microalbuminuria is an excellent indicator of microvascular injury and affects twice as many subjects with prediabetes than normoglycemic subjects. ${ }^{11}$ It is associated with both chronic kidney disease, as well as macrovascular complications. ${ }^{12}$ In the National Health and Nutrition Examination Survey, 17.7\% of subjects with prediabetes based on IFG had chronic kidney disease, compared with $10.6 \%$ without diabetes or prediabetes. ${ }^{13}$ In the MONICA (Monitoring Trends and Determinants in Cardiovascular Disease) study, the prevalence of diabetic polyneuropathy was approximately increased twofold in those individuals with IFG and IGT as compared with the normal subjects. ${ }^{14}$ There are also data suggesting increased presence of retinal changes in patients with prediabetes. ${ }^{15}$ Taken together, these observations demonstrate that prediabetes is associated with health risk and economic burdens, as it can adversely impact multiple target organs. However, this condition has not been adequately addressed by regulatory agencies in terms of prevention or management, since prediabetes is not framed as a disease but rather as a risk or a "pre" stage for diabetes. ${ }^{16}$

\section{Risk factors for the progression to diabetes and screening}

An interaction of genetic predisposition, together with lifestyle and behavior, advancing age, environmental risk factors, and low education level, contributes to the risk of T2DM. ${ }^{6,17-19}$ The consensus statement from the American College of Endocrinology and the American Association of Clinical Endocrinology describe certain characteristics and concomitant conditions that increase the risk of progression to diabetes, including family history, age, obesity, dyslipidemia, ethnicity, inactivity, and prediabetes status. ${ }^{6}$ Other interesting conditions can also predispose to diabetes (Table 2). Longterm antidepressant therapy, the use of which is increasing, appears to enhance the risk of T2DM, ${ }^{20-22}$ although more investigation is needed to confirm this association..$^{23}$ The recently described condition of "new onset diabetes after transplant" is a consequence of organ transplantation due to exposure to glucocorticoids and other immunosuppressive agents. ${ }^{24}$ New onset diabetes after transplant is associated with increased mortality and morbidity, and pretransplant screening for risk factors is highly recommended. ${ }^{25}$ The intrauterine environment (shortage or excess of nutrients) is another condition related to T2DM. Low birth weight is associated with nutritional deprivation in utero, which predisposes to the "thrifty phenotype"26 leading to obesity, insulin resistance, and reduced $\beta$-cell mass in later life. On the other hand, intrauterine hyperglycemia is not only associated with increased perinatal morbidity and mortality, but also with increased lifelong risk for the exposed offspring of obesity, metabolic and cardiovascular diseases, and earlier development of T2DM. ${ }^{27,28}$ Disruption of the circadian rhythm occurs in obesity, diabetes, and cardiovascular disease and is another factor that increases risk for diabetes. ${ }^{29}$ Transcriptional alterations of the circadian locomotor output cycles kaput (CLOCK) genes in metabolic tissues lead to blunting of rhythms of glucose tolerance and insulin sensitivity. ${ }^{30}$ In adipose tissue, this results in local inflammation that may contribute to worsening of insulin resistance. ${ }^{31}$

Table 2 Characteristics and concomitant conditions that increase the risk of progression to diabetes

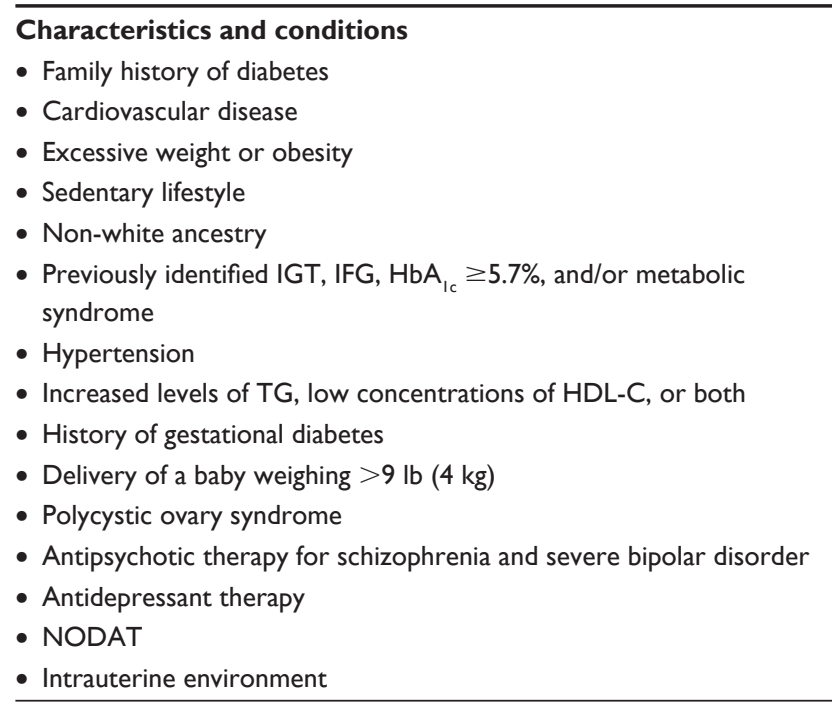

Abbreviations: $\mathrm{HbA}_{\mathrm{lc}}$, glycated hemoglobin; HDL-C, high density lipoprotein cholesterol; IFG, impaired fasting glucose; IGT, impaired glucose tolerance; NODAT, new onset diabetes after transplant; TG, triglycerides. 
International societies recommend frequent screening for diabetes among high risk individuals; however, the definition of high risk and types of risk assessment differ, as some include demographic and medical history information, while others consider measures of glycemia or oral glucose tolerance testing. ${ }^{32,33}$ Furthermore, different cohort studies indicate that diabetes risk increases at a fasting plasma glucose (FPG) below currently recommended thresholds for diagnosis of prediabetes. ${ }^{34,35}$ The Expert Committee on the Diagnosis and Classification of Diabetes Mellitus examined the sensitivity and specificity of a wide range of FPG values from several studies $(103 \mathrm{mg} / \mathrm{dL}$ in a Dutch population, $97 \mathrm{mg} / \mathrm{dL}$ in a Pima Indian population, $94 \mathrm{mg} / \mathrm{dL}$ in a Mauritius population, and $94 \mathrm{mg} / \mathrm{dL}$ in a San Antonio population) in order to identify the best cut point to optimize the prediction of diabetes, which was then set at $100 \mathrm{mg} / \mathrm{dL} .{ }^{8,36}$ Results from an intravenous glucose tolerance test study demonstrated that the first-phase insulin secretion begins to decrease once FPG values increase above $90-97 \mathrm{mg} / \mathrm{dL},{ }^{36}$ supporting the cutoff point for FPG established by the American Diabetes Association. Measurement of IGT may be a better parameter than IFG to identify individuals at risk for macrovascular complications, ${ }^{37,38}$ as IGT is more sensitive at identifying prediabetic and diabetic individuals..$^{39}$ IGT identifies a larger number of individuals who might develop diabetes as it is more common than IFG in most populations. ${ }^{8,40}$

Both IFG and IGT are insulin resistance states differing in the tissue etiology of the insulin resistance. ${ }^{41-43}$ While IFG is characterized by predominantly hepatic insulin resistance and normal muscle insulin sensitivity, IGT shows normal to slightly reduced hepatic insulin sensitivity and moderate to severe muscle insulin resistance. ${ }^{7}$ Both IFG and IGT are associated with impairment of insulin secretion. ${ }^{44}$ Individuals with IFG have severe impaired early insulin responses to the oral glucose tolerance test and improvements in insulin secretion during the second phase of the test, while individuals with IGT have impaired early and late phase of insulin secretion. ${ }^{15,45-47}$ Progressive $\beta$-cell loss characterizes the development of T2DM. In the Insulin Resistance Atherosclerosis Study, $\beta$-cell function was compromised by as much as $40 \%$ in patients with IGT and $80 \%$ in patients with diabetes. ${ }^{48}$ Whether these differences impact strategies to prevent diabetes requires further investigation. However, IGT and IFG have different implications for atherosclerotic cardiovascular disease, in which IGT is associated with metabolic syndrome and is a strong predictor of cardiovascular disease. ${ }^{49}$

Screening for IFG/IGT is highly recommended, and the most efficient sequence of testing would be an FPG followed by a 2-hour plasma glucose after a $75 \mathrm{~g}$ glucose load to demonstrate the presence of combined IFG/IGT. ${ }^{7}$ Screening for prediabetes in the overweight and obese populations has been demonstrated to be cost-effective ${ }^{50}$ More novel approaches may include the preDx ${ }^{\circledR}$ (Tethys Bioscience Inc, Emeryville, CA, USA) test, which represents a collection of variables (glycated hemoglobin [ $\mathrm{HbA}_{1 \mathrm{c}}$ ], adiponectin, C-reactive protein, ferritin, glucose, interleukin-2 receptor $\mathrm{A}$, and insulin) that have better predictive value than any single variable, which is clinically available, and a metabolomics analysis, which has suggested that glycine, lysophosphatidylcholine, and acetylcarnitine levels in plasma predict progression to diabetes. ${ }^{51-53}$

\section{Diabetes prevention}

The westernization of lifestyle characterized by decreasing physical activity and a dietary pattern with high intake of foods rich in hydrogenated fat, refined grains, and red meat is related to the increase in obesity, T2DM, and cardiovascular diseases. High saturated fat intake is associated with higher risk of IGT. ${ }^{54}$ Dietary changes including reduction of total and saturated fat and increased dietary fiber intake, along with physical activity and weight loss, can reduce the incidence of T2DM. ${ }^{55}$ Lifestyle modification focusing on improving dietary quality, physical activity, and medical intervention improves glycemic control and other cardiovascular risk factors, and is the preferred first-line treatment for the management of T2DM. Several trials have demonstrated that it is possible to prevent diabetes through lifestyle and/or medication intervention (Table 3); however, effective therapeutic strategies based on lifestyle changes, weight reduction, increasing physical activity, and eating a balanced diet are often unsuccessful due to poor compliance. ${ }^{56}$ Pharmacological interventions using different antidiabetic drugs, especially agents that improve insulin sensitivity, can prevent or at least slow the progression of prediabetes to diabetes. Bariatric surgery has also been shown to slow the progression to diabetes. Interventions should consider sex, age, ethnicity, and cultural and geographical characteristics to be feasible and to promote better compliance. Also, interventions must address education of both children and adults, food availability, and advertising, and the health system should provide incentives to encourage adoption of effective intervention for diabetes prevention. Furthermore, individual countries should develop and evaluate cost-effective, setting-specific diabetes-risk identification and prevention strategies based on their available resources. ${ }^{57}$ 
Table 3 Lifestyle and pharmacological interventions to prevent type 2 diabetes mellitus

\begin{tabular}{|c|c|c|c|c|}
\hline Study & $\mathbf{N}$ & Intervention & Treatment & Risk reduction \\
\hline \multicolumn{5}{|c|}{ Da Qing 61,62} \\
\hline \multirow[t]{2}{*}{ IGT } & 577 & Diet and exercise & 6 years & $34 \%-69 \%$ \\
\hline & & & 20 years & \\
\hline \multicolumn{5}{|c|}{ Finnish DPS ${ }^{19,55}$} \\
\hline \multirow[t]{2}{*}{ IGT } & 522 & Diet and exercise & 3 years & $58 \%$ \\
\hline & & & 7 years & \\
\hline \multicolumn{5}{|c|}{ DPP 66,77} \\
\hline \multirow[t]{2}{*}{ IGT } & 3,234 & Diet, exercise, and metformin & 2.8 years & $31 \%-58 \%$ \\
\hline & & & 10 years & \\
\hline \multicolumn{5}{|l|}{ IDPP 63} \\
\hline IGT & 531 & Diet, exercise, and metformin & 3 years & $26.4 \%-28.4 \%$ \\
\hline \multicolumn{5}{|c|}{ DREAM ${ }^{139}$} \\
\hline IGT & 5,269 & Rosiglitazone & 3 years & $60 \%$ \\
\hline \multicolumn{5}{|c|}{ STOP-NIDDM ${ }^{130,132}$} \\
\hline IGT & ।,429 & Acarbose & 3.3 years & $21 \%$ \\
\hline \multicolumn{5}{|c|}{ ACT NOW'137,138 } \\
\hline IFG & $\sim 600$ & Pioglitazone & 3.75 years & $72 \%$ \\
\hline
\end{tabular}

Abbreviations: ACT NOW, Actos Now for the Prevention of Diabetes; DPP, Diabetes Prevention Program; DPS, Diabetes Prevention Study; DREAM, Diabetes Reduction Assessment with Ramipril and Rosiglitazone Medication trial; IDPP, Indian Diabetes Prevention Programme; IGT, impaired glucose tolerance; IFG, impaired fasting glucose; STOP-NIDDM, Study to Prevent Non-insulin Dependent Diabetes.

\section{Lifestyle modification and the progression of prediabetes}

The worldwide surge in the prevalence of T2DM and obesity and the importance of prevention and control of noncommunicable diseases, as stated by the World Health Organization (WHO), ${ }^{58}$ increase the need for prevention strategies focusing on intensive lifestyle changes, as they are proven to be either cost-saving or cost-effective. ${ }^{59,60}$ Many randomized, controlled clinical trials have demonstrated a clinically significant impact of lifestyle changes in the prevention of diabetes among high risk individuals..$^{55,61-66}$ The Da Qing IGT and Diabetes Study evaluated 577 subjects with IGT who were randomized to a control group or to one of three active treatment groups (diet only, exercise only, or diet plus exercise). After a 6-year follow-up period, it was found that the diet, exercise, and diet-plus-exercise interventions were associated with $31 \%, 46 \%$, and $42 \%$ reduction in risk of developing diabetes, respectively. ${ }^{61}$ The Finnish Diabetes Prevention Study (DPS) showed that it is possible to achieve primary prevention of T2DM by changing lifestyle (diet and exercise) in subjects with IGT ( $\mathrm{n}=522$ ), reducing the risk of diabetes by $58 \%$ in the intervention group. ${ }^{55}$ The participants were randomly allocated either into the control group or an intensive lifestyle intervention group, and the cumulative incidence of diabetes after 4 years was $11 \%$ in the intervention group and $23 \%$ in the control group. ${ }^{65}$ The Diabetes Prevention Program (DPP) Research Group randomized 3,234 individuals with IFG and IGT to receive placebo, metformin, or a lifestyle intervention program, and after an average of 2.8 years, the incidence of diabetes was $11.0,7.8$, and 4.8 cases per 100 person-years, respectively. ${ }^{66}$ These clinical trials establish the potential to prevent T2DM in high-risk individuals through a lifestyle intervention focusing on achievement and maintenance of weight reduction by consuming a healthy diet and increasing physical activity. Weight loss has the greatest effect in preventing and treating T2DM. ${ }^{66,67}$ However, results from the Da Qing IGT and Diabetes Study showed a beneficial effect even with relatively small reduction in body mass index (BMI), as participants were generally lean. Thus, other lifestyle issues are important to the pathogenesis of T2DM, despite the fact that weight may work as a summary indicator of several dietary and activity factors. ${ }^{60}$ Overall, these data highlight the importance of tailoring lifestyle interventions to prevent T2DM within distinct populations.

In the Finnish DPS, post hoc analyses showed that adopting a diet with moderate fat and high dietary fiber content ${ }^{65}$ in addition to weight loss and increased physical activity, ${ }^{68}$ was independently associated with diabetes risk reduction. Thus, an appropriate strategy of diet and physical activity that promotes weight loss can prevent diabetes. The most successful nutritional strategy for both prevention and treatment of T2DM is one that the individual can adapt and follow permanently. ${ }^{69}$ Extreme dietary restriction and avoidance of certain food groups, such as carbohydrates or sources of fats, might be efficient for weight loss in the short-term but may not be sustainable in the long-term. ${ }^{70} \mathrm{~A}$ dietary plan should take into consideration culture, food availability, and personal preferences, and yet follow recommendations that encourage a high intake of fruit and vegetables, unrefined grains with natural high fiber content, vegetable oil with low content of saturated fat (such as olive 
oil), nuts, legumes, low-fat dairy and fish as sources of protein, and limit the intake of highly processed foods. ${ }^{71}$

Physical inactivity is an important lifestyle factor related to chronic disease morbidity and premature mortality worldwide. ${ }^{72,73}$ Interventions focusing on increasing physical activity improve glucose tolerance and reduce the risk of T2DM in high-risk individuals, ${ }^{74}$ regardless of bodyweight. ${ }^{68,75}$ The WHO recommendation on physical activity for adults is at least 150 minutes per week of moderate-intensity aerobic physical activity, or 75 minutes per week of vigorous-intensity aerobic physical activity, or an equivalent combination of moderate and vigorous-intensity activity. Physical exercises can be performed in multiple shorter bouts, of 10 minutes each, then adding together the time spent during each of these bouts until meeting the goal of 150 minutes of physical exercise per week, eg, 30 minutes of moderate-intensity activity five times per week. ${ }^{76}$ Also, the recommendations suggest that adults perform musclestrengthening activities two or more days per week involving all major muscle groups. ${ }^{76}$ The Diabetes Prevention Program lifestyle intervention demonstrated beneficial effect on glycemic control in those with prediabetes with 150 minutes per week of moderate-intensity exercise. ${ }^{66}$

\section{Sustained benefits of lifestyle modification}

Lifestyle interventions are effective in sustaining behavioral changes that result in long-term reduction in diabetes incidence. The extended follow-up of the Finnish DPS assessed whether the originally achieved lifestyle changes and risk reduction remained after discontinuation of active counseling. The investigators found that beneficial lifestyle changes achieved by participants in the intervention group were maintained after the discontinuation of the intervention, and the marked reduction in the cumulative incidence of T2DM was sustained. ${ }^{65}$ Likewise, the 10 -year follow-up of the DPP showed that the cumulative incidence of diabetes remained lowest in the lifestyle intervention group. ${ }^{77}$ The 20-year follow-up of the Da Qing IGT and Diabetes Study revealed that participants in the intervention group spent an average of 3.6 fewer years with diabetes than those in the control group, and diabetes could be prevented or delayed for up to 14 years after the active intervention. ${ }^{62}$ However, there was no significant difference between the intervention and control groups in the rate of first cardiovascular events. ${ }^{62}$ Similar results were found in the Finnish DPS 10-year follow-up, where mortality and cardiovascular morbidity were not different between the intervention and control groups. ${ }^{19}$

\section{Implementing lifestyle modification at a community level}

It has been a challenge to translate the message of these successful intervention trials preventing T2DM at a population level, particularly identifying the most effective methods of prevention in various societies and cultural settings. ${ }^{78}$ The resources available at a clinical practice are typically limited when compared with experimental settings, which could be an important factor influencing translation and delivery of evidence-based diabetes prevention programs. ${ }^{57,79,80}$ Many national and local authorities and health care providers around the world have started programs and activities to prevent T2DM and its complications, ${ }^{79,81-86}$ and a European group of experts has prepared evidence-based guidelines on T2DM prevention, ${ }^{87}$ a toolkit for diabetes prevention, ${ }^{88}$ and guidelines to evaluate quality indicators for the prevention of T2DM. ${ }^{89}$ The toolkit for the prevention of diabetes (IMAGE project) is a practical guideline that includes all the necessary information to build a T2DM prevention program (management, financial, intervention, quality assurance aspects, and how to translate this knowledge into practice). ${ }^{88}$ The major challenge now is to disseminate these guidelines and implement them at different settings and levels in the community. ${ }^{90}$

Several community-based studies involving primary care and occupational health care have found significant reductions in T2DM risk factors through lifestyle intervention programs. ${ }^{83,91-95}$ However, it has not been possible to evaluate the impact of these interventions on the incidence of diabetes, as most of the studies were small, with follow-up limited to just 1 year. The Finnish National Diabetes Prevention Program (FIN-D2D) was implemented in the Finnish primary health care system, with strategies of implementing screening and lifestyle interventions in individuals at high risk of T2DM as part of routine primary care. ${ }^{82,83}$ After 1 year, the FIN-D2D group reported that recruiting high-risk subjects for the program was found to be simple and the program was easy to use, and a moderate weight loss was effective to reduce the risk of developing T2DM. ${ }^{83}$ The Active Prevention in High-Risk Individuals of Diabetes Type 2 in and Around Eindhoven (APHRODITE) study is a low intensity and low cost intervention that investigated the effectiveness and feasibility of T2DM prevention through lifestyle intervention in Dutch general practice. The study showed that T2DM could be significantly reduced by lifestyle counseling. ${ }^{85}$ Three other community studies, Diabetes Education and Prevention with a Lifestyle Intervention Offered at the YMCA (DEPLOY), ${ }^{92}$ Prevention of Diabetes Self-management Program (PREDIAS), ${ }^{93}$ and the Australian Great Green 
Triangle (GGT) Diabetes Prevention Study ${ }^{94}$ also showed beneficial effects of lifestyle on risk factors for T2DM. The DEPLOY study compared the results of two different lifestyle intervention approaches in adults who attended a diabetes risk-screening event at one of two semi-urban YMCA facilities. Study participants $(n=92)$ were allocated to a group-based DPP lifestyle intervention delivery by the YMCA or standard advice alone (controls). Results showed that YMCA wellness instructors can be trained to deliver a group-based DPP lifestyle intervention, and the body mass changes after 6 and 12 months in the intervention group were similar to the DPP study. ${ }^{92}$ The PREDIAS program randomly assigned 182 individuals at high risk for T2DM to either an intervention program consisting of 12 group sessions aimed at lifestyle modification, or a control group who received the same written information but did not attend any group sessions. The lifestyle program was able to reduce diabetes risk by promoting weight loss and modifying eating behavior and physical activity significantly. ${ }^{93}$ The GGT Diabetes Prevention Project was implemented in a primary health care setting in Australia with 237 individuals using the intervention model based on the Finnish DPS. Results showed significant changes in weight, waist circumference, glucose and lipids, and psychological measures. ${ }^{94}$ Although the results of these studies are encouraging, there were challenges in recruiting individuals at high risk, suggesting that a range of different approaches may be needed to engage people that are at risk for developing diabetes. ${ }^{57}$ The DE-PLAN (Diabetes in Europe - Prevention using Lifestyle, Physical Activity and Nutrition intervention) in Greece identified high-risk individuals through a questionnaire that required minimal effort to complete and found that recruitment from workplaces was more successful when compared with recruitment from primary care centers. ${ }^{95}$

The outcomes of the studies were related to the participant's initial risk profile, in which those with a less favorable profile had more improvement and increased motivation to lose weight, eat healthier, and exercise more. Strategies to support behavior change still need improvements as individuals from different backgrounds and cultures might need distinct actions to support lifestyle changes. ${ }^{71}$ Partner support is an important factor for successful behavioral change, and the level of the health professional experience (ie, nurse practitioner) may facilitate the intervention success. ${ }^{85}$ Social support is also related to effectiveness of behavior changes, especially in weight-loss programs, ${ }^{87}$ while lack of family support can be a major barrier for achieving ${ }^{86}$ and maintaining ${ }^{96}$ behavior change in intervention programs to prevent T2DM.
Recently, two large community health centers in Massachusetts were assessed for translating evidence-based diabetes intervention to disadvantaged groups. The study demonstrated suboptimal quality of care for T2DM prevention, including lack of information of factors associated with diabetes risk on more than half of the medical records reviewed, and limited documentation of counseling and criteria for the interventions on risk factors. Providers recognized patient's cultural traditions, attitudes, and low motivation for the intervention as important challenges, while patients expressed interest and were concerned about their diabetes risk, even though expressing limited ability to initiate and maintain lifestyle changes. This study showed that translation efforts are needed to implement interventions in real world community health centers to prevent diabetes in individuals at risk ${ }^{86}$ High quality training for providers is essential for implementing a successful intervention program, which should include knowledge about the relationship between lifestyle behavior and the progression of T2DM, skills for assessing diet and physical activity, and techniques for supporting the initiation and maintenance of behavioral changes. ${ }^{71,87,95,97}$ Developing a research team that shares racial, ethnic, and cultural backgrounds with the population being served can facilitate development of successful recruitment strategies, influence the retention of participants, and enhance trust in the outcomes of study ${ }^{80}$ It is important that there are members that guide teams in community intervention programs that are from the same neighborhoods, share the same or similar demographic and comorbid conditions, and/or have a vested interest in the issues being addressed in the program..$^{79,80,98,99}$

\section{Community-based changes}

Multiple external barriers to lifestyle changes, limited understanding of diabetes risk and prevention, ${ }^{79}$ and limited behavior change skills are important challenges that interfere with the effective implementation of diabetes prevention programs on a larger scale. ${ }^{57}$ Barriers to effective program implementation include geographical location; vernacular; language; culture (racial, ethnic, organizational structurebureaucratic, and mission); and whether the community is open to new approaches, while not discarding traditional rituals and customs. ${ }^{98}$ Community-based participatory programs can address barriers via multiple levels promoting collaborative relationships between community members, educators, clinicians, researchers, university programs/ interns, and agencies, and results in healthy lifestyle behaviors in the designated population. This strategy not only provides insight into barriers and potential solutions, but 
helps promote individualization and buy-in of programs from all corresponding parties, providing greater access and trust with vulnerable and hard to access individuals in the community and, thus, facilitates the sustainability of programs. ${ }^{100-116}$

Public awareness regarding prediabetes and diabetes needs to be disseminated at various levels from educating the appropriate government representatives and community leaders and raising awareness through community events including town hall meetings, health fairs, and seminars at school meetings, community centers, and clinics. Prevention and management programs can be held for children from 4 to 18 years of age during summer and after-school programs; programs for the elderly can be held at senior centers or nutrition centers; diabetes and pregnancy programs can be held at clinic locations; and diabetes screenings, education, and management programs can be presented at community centers, churches, and clinics. ${ }^{102}$

Another strategy to increase partnerships in the community is to train the next generation of researchers, educators, and clinicians from outlying colleges and universities which can defray some costs of intervention programs while concurrently disseminating these programs into the community. Professors often find it difficult to locate placements for their students in real clinical life scenarios whereby they can apply the conceptual knowledge and skills that they have been taught. Specific measurable goals and projects need to be carefully outlined for each student so that they are trained in their respective course syllabus requirements and develop knowledge and skills beyond the classroom while still achieving and sustaining the goals of the community program. ${ }^{117,118}$
With community participation and buy-in, innovative and individualized approaches can provide the foundation toward decreasing health disparities in minority and other vulnerable populations that are disproportionately afflicted with obesity and diabetes. Although the process can be slow, taking months to years to formulate these relationships, they are worth the effort to create solid changes and sustainability of program goals and strategies. ${ }^{80,111,112,119-125}$

\section{Pharmacotherapy and the progression of prediabetes}

Randomized clinical trials listed in Table 3 have demonstrated that both lifestyle changes and pharmacological intervention can reduce the risk of T2DM in high-risk individuals. Table 4 summarizes the classes of medications reviewed below, their mechanism of action and the trials demonstrating the benefit.

\section{Biguanides}

The two major intervention studies that included metformin, which suppresses hepatic glucose production, reportedly by stimulating the AMPK (adenosine monophosphate-activated protein kinase) pathway in the liver, ${ }^{126}$ were the DPP study performed in the United States and the Indian Diabetes Prevention Programme (IDPP-1) study performed in India. In the DPP trial, 1,073 participants with IGT were allocated to 850 mg of metformin twice a day and 1,082 participants were allocated to placebo, and were followed-up for a median period of 2.8 years. At the end of the study, metformin reduced the incidence of T2DM by $31 \%$ compared with placebo. ${ }^{6}$ After the end of the original study, a 10-year follow-up was

Table 4 Pharmacologic therapy in the prevention of T2DM

\begin{tabular}{|c|c|c|c|}
\hline Therapeutic intervention & Mechanism of action & Result of trial & Study \\
\hline Biguanides & AMPK activation & Reduction in the incidence of T2DM & $\begin{array}{l}\text { Knowler et al }{ }^{66} \\
\text { Ramachandran et } a^{63}\end{array}$ \\
\hline Alpha glucosidase inhibitors & Slow intestinal carbohydrate absorption & Reduction in the incidence of T2DM & Chiasson et $\mathrm{al}^{130}$ \\
\hline Lipase inhibitors & Slow intestinal fat absorption & $\begin{array}{l}\text { Reduction in the incidence of T2DM } \\
\text { Promotion of weight loss }\end{array}$ & Torgerson et $\mathrm{al}^{142}$ \\
\hline DPP-4 inhibitors & Increase GLP-I levels & Improvement in glycemic control & Rosenstock et al ${ }^{153}$ \\
\hline Thiazolidinediones & Activation of PPAR- $\gamma$ & $\begin{array}{l}\text { Improvement in insulin sensitivity } \\
\text { Prevention on the progression to T2DM }\end{array}$ & $\begin{array}{l}\text { Buchanan et al } \\
\text { Xiang et al } \\
\text { Defronzo et } \mathrm{al}^{136} \\
\text { DeFronzo et } \mathrm{al}^{138} \\
\text { Gerstein et } \mathrm{al}^{139}\end{array}$ \\
\hline GLP-I receptor agonist & Activation of GLP-I receptor & $\begin{array}{l}\text { Decrease in } A_{l c} \\
\text { Promotion of weight loss }\end{array}$ & $\begin{array}{l}\text { Rosenstock et } \mathrm{al}^{158} \\
\text { Astrup et } \mathrm{al}^{159}\end{array}$ \\
\hline Sympathomimetic amines & Appetite suppressant & Promotion of weight loss & $\begin{array}{l}\text { Gadde et al }{ }^{171} \\
\text { Garvey et } \text { al }^{172}\end{array}$ \\
\hline
\end{tabular}

Abbreviations: AMPK, adenosine monophosphate-activated protein kinase; DPP-4, dipeptidyl peptidase-IV; GLP, glucagon-like peptide; PPAR, peroxisome proliferatoractivated receptor; T2DM, type 2 diabetes mellitus. 
offered to the active participants who continued to follow the original study protocol. Diabetes incidence was reduced by $18 \%$ in the metformin group in comparison with placebo after 10 years from the initial randomization. ${ }^{77}$ The IDPP-1 study showed a $25 \%$ relative reduction in T2DM for those who used metformin $250 \mathrm{mg}$ twice a day. ${ }^{63} \mathrm{~A}$ meta-analysis of 31 randomized studies including 4,570 participants with at least 8 weeks of metformin use showed that the incidence of T2DM was reduced by $40 \%$, with an absolute risk reduction of $6 \% .{ }^{127}$ Metformin therapy is able to improve the activation of CLOCK genes in some but not all peripheral tissues. New therapies are needed to act either on the central and/or the peripheral CLOCKs to prevent the alterations in circadian rhythm thereby preventing the progressive insulin resistance and loss of $\beta$-cell function that leads to T2DM. ${ }^{128}$

\section{Alpha glucosidase inhibitors}

Another antihyperglycemic agent for treating T2DM is the alpha-glucosidase inhibitor acarbose, which slows carbohydrate absorption and decreases postprandial hyperglycemia. ${ }^{129}$ Although its use is not generally associated with weight loss, the mechanism of action is to decrease carbohydrate breakdown and thereby absorption, thus decreasing the workload on the pancreas. The Study to Prevent Non-insulin Dependent Diabetes (STOP-NIDDM) was carried out in 1,429 participants with IGT randomized to $100 \mathrm{mg}$ of acarbose or placebo, three times a day for a mean period of 3.3 years. The relative reduction of T2DM was $35.8 \%$ in the acarbose group when compared with placebo. The study also showed surprising relative reductions in myocardial infarction (91\%) and new onset hypertension $(34 \%)$ in treated IGT patients. ${ }^{130-132}$

\section{Thiazolidinediones}

Experimental and clinical evidence suggest that thiazolidinediones improve insulin sensitivity, restore pancreatic $\beta$-cell function, promote fat removal from the liver, and attenuate inflammation. ${ }^{133,134}$ Troglitazone was tested in the Troglitazone in Prevention of Diabetes Study (TRIPOD) in high-risk Hispanic women. Treatment with troglitazone delayed or prevented the onset of T2DM, and the protective effect was associated with the preservation of pancreatic $\beta$-cell function and appeared to be mediated by a reduction in the secretory demands placed on the $\beta$-cell by chronic insulin resistance. ${ }^{135}$ The Pioglitazone In Prevention Of Diabetes (PIPOD) study was conducted to evaluate $\beta$-cell function, insulin resistance, and the incidence of diabetes during treatment with pioglitazone in Hispanic women with prior gestational diabetes who had completed participation in the TRIPOD study. Comparison of changes in $\beta$-cell compensation for insulin resistance across the TRIPOD and PIPOD studies revealed that pioglitazone stopped the decline in $\beta$-cell function that occurred during placebo treatment in the TRIPOD study and maintained the stability of $\beta$-cell function that had developed during troglitazone treatment in the TRIPOD study. ${ }^{136}$ Pioglitazone use to prevent progression of diabetes was observed for an average of 3.75 years in the randomized placebo-controlled study ACT NOW (Actos Now for the Prevention of Diabetes), in which 602 patients with IGT received either $45 \mathrm{mg} /$ day pioglitazone or placebo. As compared with placebo, pioglitazone reduced the risk of conversion of IGT to T2DM by $72 \%$, but was associated with significant weight gain and edema. ${ }^{137,138}$ Rosiglitazone was tested alone in two randomized studies: the Diabetes Reduction Assessment with Ramipril and Rosiglitazone Medication (DREAM trial) ${ }^{139}$ and the Canadian Normoglycemia Outcomes Evaluation (CANOE). ${ }^{140}$ The DREAM trial recruited 5,269 patients with IFG, IGT, or both, and demonstrated that rosiglitazone was highly effective in reducing the incidence of T2DM by $60 \%$ in comparison with placebo. ${ }^{139}$ In order to assess the overall cardiovascular safety of rosiglitazone, when added to metformin or sulfonylurea treatment, the RECORD trial (Rosiglitazone Evaluated for Cardiac Outcomes and Regulation of Glycaemia in Diabetes) demonstrated that rosiglitazone does not increase the risk of overall cardiovascular morbidity or mortality compared with standard glucoselowering drugs. ${ }^{141}$ The CANOE study included 207 patients with IGT who received a combination of rosiglitazone ( $2 \mathrm{mg}$ ) and metformin $(500 \mathrm{mg})$ twice daily for a median period of 3.9 years. The low-dose combination therapy with rosiglitazone and metformin was highly effective in the prevention of T2DM, with a low incidence of clinically relevant adverse effects. Relative and absolute risk reduction of T2DM in the active treatment group was $66 \%$ and $26 \%$, respectively, compared with placebo. ${ }^{140}$

\section{Lipase inhibitors}

The lipase inhibitor orlistat was utilized in the Xenicalbased Prevention of Diabetes in Obese Subjects study, a double-blind, prospective study, that randomized 3,305 obese patients to lifestyle changes plus either orlistat $120 \mathrm{mg}$ or placebo, three times daily for 4 years. Compared with lifestyle changes alone, orlistat plus lifestyle changes resulted in a $37.3 \%$ decrease in the risk of developing diabetes over the 4 years and produced greater weight loss in this clinically representative obese population. In addition, independent of 
orlistat or placebo treatment, the relative risk of developing T2DM was greater in the patients with IGT than in those with normal glucose tolerance. ${ }^{142}$

\section{Insulin}

The ORIGIN (Outcome Reduction with Initial Glargine Intervention) was the first study to evaluate the effect of early treatment with basal insulin compared with standard treatment, in a large multinational multicenter randomized trial of individuals with prediabetes and early T2DM who had high cardiovascular risk. The trial demonstrated that microangiopathy was reduced in individuals with $\mathrm{HbA}_{1 \mathrm{c}}>6.4 \%$ and that glycemic control prevents diabetes progression for 5 years by keeping $\mathrm{HbA}_{1 \mathrm{c}}$ around $6.5 \%{ }^{143}$ Results from the DPPOS (Diabetes Prevention Program Outcome Study) show a 56\% reduction in diabetes incidence in high-risk individuals who revert to normal glucose regulation, no matter how this reversion is achieved, as long as the intervention is early (prediabetes) and can restore normal glucose regulation. ${ }^{144}$

\section{Bile acid sequestrants}

In small studies, several newer agents were administered to patients with prediabetes, but not for diabetes prevention. The bile acid sequestrant colesevelam has been shown to improve insulin sensitivity and $\beta$-cell function similarly in subjects with prediabetes (IFG) and T2DM. ${ }^{145}$ Although the mechanism of action is unknown, the observation that $\mathrm{A}_{1 \mathrm{c}}$ improved after colesevelam treatment in the lipid-lowering trials led to studies of glucose regulation. After demonstration of improvement in oral glucose tolerance, a randomized study was performed with 216 adults with untreated prediabetes. Participants were randomized 1:1 to colesevelam $3.75 \mathrm{~g} /$ day or placebo. Treatment with colesevelam was associated with a significant reduction in $\mathrm{A}_{1 \mathrm{c}}$ and a greater number of subjects attaining a normal FPG and an $\mathrm{A}_{1 \mathrm{c}}<6.0 \%$ compared with placebo. ${ }^{146} \mathrm{~A}$ Hispanic subgroup was analyzed from this study (colesevelam, $n=77$; placebo, $n=76$ ) in whom they found a significant mean reduction in both $\mathrm{A}_{1 \mathrm{c}}$ and FPG levels with colesevelam ( $P \leq 0.02$ for both). A FPG level $<100 \mathrm{mg} / \mathrm{dL}$ was achieved in $44 \%$ of colesevelam recipients, compared with $23 \%$ of placebo recipients $(P<0.05) .{ }^{147}$

\section{Dipeptidyl peptidase-IV (DPP-4) inhibitors}

DPP-4 inhibitors, whose primary mechanism of action is enhancement of the activity of endogenous glucagon-like peptide (GLP)-1 by preventing its degradation, improve gly- cemic control in hyperglycemic patients. ${ }^{148-150}$ GLP-1 stimulates insulin secretion and inhibits glucagon secretion, but is not active when the plasma glucose level falls to $60 \mathrm{mg} / \mathrm{dL}$ or less, thus DPP-4 inhibitors do not cause hypoglycemia. ${ }^{151,152}$ The first evidence regarding the effects of a DPP-4 inhibitor in a prediabetic population was a 12 -week, double-blind, randomized, parallel-group study comparing vildagliptin (50 mg once daily) and placebo, conducted in 179 subjects with IGT (2-hour glucose $9.1 \mathrm{mmol} / \mathrm{L}, \mathrm{A}_{1 \mathrm{c}}$ 5.9\%). The known effects of vildagliptin on incretin levels and islet function in T2DM were reproduced in subjects with IGT, with a $32 \%$ reduction in postprandial glucose and no evidence of hypoglycemia or weight gain. ${ }^{153}$

\section{GLP-I receptor agonists}

Subcutaneous injection of native GLP-1 in people with uncontrolled T2DM can reduce both $\mathrm{A}_{1 \mathrm{c}}$ and bodyweight. ${ }^{154}$ The mechanism of the weight loss has been proposed as a combination of decreased food intake due to GLP-1 effects on gastrointestinal motility and direct effects of GLP-1 on the central nervous system. These data have led to speculation that GLP-1 treatment of prediabetes could also facilitate weight loss and improve $\mathrm{A}_{1 \mathrm{c}}$, thereby slowing the progression to T2DM. ${ }^{155,156}$ Data from animal models have shown that treatment with the GLP-1 human analog liraglutide can prevent the progression not only from prediabetes to diabetes but also prevent high-risk animals from developing prediabetes. Studies in prediabetic rats have demonstrated that 12 weeks of treatment was associated with restoration of islet structure and reversal of IFG, IGT, abnormal lipid profile, and inflammatory markers. ${ }^{157}$ Human studies using exenatide or liraglutide have demonstrated significant weight loss and glucose tolerance improvement in patients with IFG or IGT, with the beneficial effects apparent by 20-24 weeks and, in the case of liraglutide, sustained for as long as 2 years of treatment. ${ }^{158,159}$ Additional trials are ongoing in different populations, such as the Effects of Exenatide on Post-Prandial Glucose Excursions and Vascular Health in Obese/Pre-Diabetic Young Adults (Clinical Trials NCT00845559). ${ }^{160}$

\section{Bariatric surgery prevents progression to diabetes}

Although this review is focused on lifestyle modification and pharmacologic treatment on the prevention of diabetes, bariatric surgery should be considered as a complement to any pharmacologic agent. Initial retrospective studies have suggested that bariatric surgery prevents progression to T2DM, albeit in low-risk populations. ${ }^{161-163}$ While surgery 
is not able to "cure" T2DM, some do consider it a near cure, with the marked improvements in $\mathrm{A}_{1 \mathrm{c}}$ accompanied by decreases in number of medications and/or insulin doses. ${ }^{162}$ These responses are now referred to as "remission." This benefit is likely to extend to individuals with prediabetes. Bariatric surgery, as compared with usual care, reduces the long-term incidence of T2DM by $78 \%$ in obese individuals and by $87 \%$ in individuals with IFG. ${ }^{161}$ Again, it is not known whether the benefits are merely due to weight loss. The possibility that bariatric surgery has a direct effect on insulin resistance has long been debated due to the observation that insulin requirements decrease dramatically in the first 12-24 hours after surgery, prior to the onset of weight loss, and are more pronounced than benefits observed with typical intra-abdominal surgeries. The type of surgery is also under close scrutiny to determine whether structural alterations in the gastrointestinal anatomy have differential impacts on glucose regulation. ${ }^{161-163}$

Transoral gastroplasty (TOGA) is a safe and less invasive procedure than traditional bariatric surgery. Leccesi et al ${ }^{164}$ studied the effects of TOGA on the risk of progression from prediabetes to overt T2DM or on regression from diabetes or prediabetes to a lower risk category. The study enrolled 50 subjects aged 18-60 years with a BMI between 35 and $55 \mathrm{~kg} / \mathrm{m}^{2}$. TOGA improved glucose disposal, with regression of diabetes to normal glucose tolerance or IGT and regression of IGT and IFG to normal glucose tolerance in half of the cases. Interestingly, regressors showed a much larger increase of GLP-1 levels than progressors.

\section{Other newer agents may be useful in prediabetes}

The quick-release formulation of bromocriptine, known

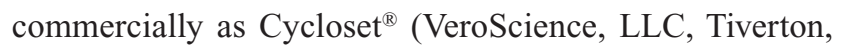
RI, USA) (bromocriptine mesylate), also has potential for treating prediabetes, as its unique mechanism of action is mediated through resetting central circadian organization of monoamine neuronal activities, thereby improving the alterations in hepatic glucose production, lipid synthesis, and mobilization associated with obesity and insulin resistance. ${ }^{165}$ Bromocriptine is a sympatholytic dopamine D2 receptor agonist that can exert inhibitory effects on serotonin turnover in the central nervous system. ${ }^{166}$

Specifically, bromocriptine reduces ventromedial, arcuate, and paraventricular hypothalamic drive for increased hepatic glucose production, lipid synthesis and mobilization, and insulin resistance. ${ }^{167}$ Administration in the early hours of the light cycle prevents or reverses seasonal weight gain, insulin resistance, and hyperinsulinemia, as well as decreases endogenous (hepatic) glucose production in mammals. ${ }^{168-171}$ Through improving the underlying disease process of lipotoxicity and insulin resistance, it is likely that quick-release bromocriptine would be beneficial in prediabetes; thus, an intervention trial is warranted with this interesting agent.

Sustained weight loss has been demonstrated to improve $\beta$-cell function; therefore, the use of medications to facilitate and, perhaps, maintain weight loss would be expected to improve insulin resistance and preserve or enhance $\beta$-cell function. It is not known whether any of the currently available weight loss agents have any intrinsic benefit in preventing the progression from prediabetes to diabetes. The mechanistic data from the available agents, phentermine, topiramate, and lorcaserin, do not suggest a benefit to $\beta$-cell function or insulin resistance beyond that of weight loss. However, registration trials are required to assess metabolic parameters so there are data related to the impact on glucose changes in the obese subjects. The impact on glucose control was assessed in a 56-week Phase 3 trial of 2,487 subjects who were overweight or obese (aged 18-70 years), with a BMI of $27-45 \mathrm{~kg} / \mathrm{m}^{2}$ and two or more comorbidities (hypertension, dyslipidemia, diabetes or prediabetes, or abdominal obesity). Subjects were randomized to placebo, once-daily phentermine $7.5 \mathrm{mg}$ plus topiramate $46.0 \mathrm{mg}$, or once-daily phentermine $15.0 \mathrm{mg}$ plus topiramate $92.0 \mathrm{mg}$ in a 2:1:2 ratio in 93 centers in the USA. The combination of phentermine and topiramate, with office-based lifestyle interventions, was associated with a significant decrease in $\mathrm{A}_{1 \mathrm{c}}(-0.4 \%)$ compared with the control group $(-0.1 \%) .{ }^{172}$ These benefits were sustained in the double-blind 52-week extension study, where the annualized incidence rates for progression to T2DM among subjects without diabetes at baseline were $3.7 \%, 1.7 \%$, and $0.9 \%$ in the placebo, $7.5 / 46 \mathrm{mg}$, and $15 / 92 \mathrm{mg}$ treatment groups, respectively. These data indicate a $54 \%$ reduction in the progression to T2DM in subjects receiving 7.5/46 $\mathrm{mg}$ and a $76 \%$ reduction in subjects taking $15 / 92 \mathrm{mg}$, compared with placebo. ${ }^{173}$ The authors attribute the lower rates of incident diabetes with phentermine plus topiramate to the weight loss, without suggesting a direct effect of the combination of the phentermine plus topiramate. ${ }^{174,175}$ Garvey et al ${ }^{174}$ recently demonstrated significant weight loss and reduced progression to T2DM in subjects with prediabetes and/or metabolic syndrome at baseline over 108 weeks' treatment with phentermine and topiramate extended-release. Subjects receiving either $7.5 \mathrm{mg}$ of phentermine plus $46.0 \mathrm{mg}$ of 
topiramate or $15.0 \mathrm{mg}$ of phentermine plus $92.0 \mathrm{mg}$ of topiramate experienced $10.2 \%$ and $12.1 \%$ weight loss and a reduction of $70.5 \%$ and $78.7 \%$ in the incidence rate of T2DM, respectively. ${ }^{174}$

The exact mechanism of action for lorcaserin is not clearly understood, but it is believed to act as an agonist at central serotonin subtype $2 \mathrm{C}$ (5-HT2C) receptors located on hypothalamic pro-opiomelanocrotin neurons. Lorcaserin shows high selectivity for the 5-HT2C receptor subtype, with minimal activity at 5-HT2B or 5-HT2A receptor subtypes. Agonism of the 5-HT2C receptor is believed to reduce food intake and increase satiety, leading to weight loss. Earlier anti-obesity agents, such as dexfenfluramine, were withdrawn from the market because of an association with valvular heart disease thought to be caused by agonism at the 5-HT2B receptor. There is no data specifically reporting the impact of lorcaserin on prediabetes. The BLOOM-DM (Behavioral Modification and Lorcaserin for Obesity and Overweight Management in Diabetes Mellitus) trial showed a statistically significant improvement in FPG and $A_{1 c}$ in subjects with T2DM when treated with lorcaserin versus placebo for 52 weeks. ${ }^{175}$ The BLOSSOM (Behavioral modification and Lorcaserin Second Study for Obesity Management) and BLOOM trials did show improvements in glucose after 52 and 104 weeks, respectively, of therapy but both specifically excluded people with known T2DM and did not report glucose-related data on prediabetes subgroups. ${ }^{176,177}$ Nonetheless, the lifestyle intervention trials have shown that loss of as little as $5 \%-10 \%$ of bodyweight can have beneficial effects on preventing the development of T2DM; thus, one would predict that the weight loss demonstrated with lorcaserin will have a similar beneficial effect.

\section{Conclusion}

We are facing a global epidemic of T2DM and obesity. Studies indicate T2DM can be prevented in high-risk individuals through lifestyle modification, pharmacologic interventions, and bariatric surgery. However, the translation of this research to a population level, especially finding the most effective methods of preventing T2DM in various societies and cultural settings is challenging, but is a crucial priority. Public health programs focused on increasing personal awareness of risk, community support and education, and government resources are necessary to slow the progression of prediabetes to T2DM. Importantly, health care systems need to recognize "prediabetes" as a disease and to use this term to promote programs that are culturally and geographically appropriate. Further research is needed to determine how early interventions should be implemented and sustained.

\section{Author contributions}

All authors contributed substantially to the analysis and interpretation of data from published work. KCPM wrote the first draft, and all authors reviewed and contributed to the final version.

\section{Acknowledgments}

The authors thank the Science without Borders program (Ciencia sem Fronteiras, CNPq), Brazil, for providing a postdoctoral scholarship.

\section{Disclosure}

The authors disclose no conflicts of interest in this work.

\section{References}

1. Chan JC, Malik V, Jia W, et al. Diabetes in Asia: epidemiology, risk factors, and pathophysiology. JAMA. 2009;301:2129-2140.

2. Yang W, Lu J, Weng J, et al. Prevalence of diabetes among men and women in China. New Engl J Med. 2010;362:1090-1101.

3. Misra A, Khurana L. Obesity and the metabolic syndrome in developing countries. J Clin Endocrinol Metab. 2008;93:S9-S30.

4. International Diabetes Federation. IDF Diabetes Atlas. Brussels, Belgium: International Diabetes Federation; 2013.

5. American Diabetes Association. Economic costs of diabetes in the US in 2012. Diabetes Care. 2013;36:1033-1046.

6. Garber AJ, Handelsman Y, Einhorn D, et al. Diagnosis and management of prediabetes in the continuum of hyperglycemia: when do the risks of diabetes begin? A consensus statement from the American College of Endocrinology and the American Association of Clinical Endocrinologists. Endocr Pract. 2008;14:933-946.

7. Nathan DM, Davidson MB, DeFronzo RA, et al. Impaired fasting glucose and impaired glucose tolerance: implications for care. Diabetes Care. 2007;30:753-759.

8. Genuth S, Alberti KG, Bennett P, et al. Follow-up report on the diagnosis of diabetes mellitus. Diabetes Care. 2003;26:3160-3167.

9. Hsueh WA, Orloski L, Wyne K. Prediabetes: the importance of early identification and intervention. Postgrad Med. 2010;122:129-143.

10. Grundy SM. Pre-diabetes, metabolic syndrome, and cardiovascular risk. J Am Coll Cardiol. 2012;59:635-643.

11. Tapp RJ, Shaw JE, Zimmet PZ, et al. Albuminuria is evident in the early stages of diabetes onset: results from the Australian Diabetes, Obesity, and Lifestyle Study (AusDiab). Am J Kidney Dis. 2004;44: 792-798.

12. Perkovic V, Verdon C, Ninomiya T, et al. The relationship between proteinuria and coronary risk: a systematic review and meta-analysis. PLoS Med. 2008;5:e207.

13. Plantinga LC, Crews DC, Coresh J, et al. Prevalence of chronic kidney disease in US adults with undiagnosed diabetes or prediabetes. Clin J Am Soc Nephrol. 2010;5:673-682.

14. Ziegler D, Rathmann W, Dickhaus T, Meisinger C, Mielck A. Prevalence of polyneuropathy in pre-diabetes and diabetes is associated with abdominal obesity and macroangiopathy: the MONICA/KORA Augsburg Surveys S2 and S3. Diabetes Care. 2008;31:464-469.

15. Tabak AG, Herder C, Rathmann W, Brunner EJ, Kivimaki M. Prediabetes: a high-risk state for diabetes development. Lancet. 2012;379:2279-2290.

16. Eldin WS, Emara M, Shoker A. Prediabetes: a must to recognise disease state. Int J Clin Pract. 2008;62:642-648.

17. Grarup N, Andersen G. Gene-environment interactions in the pathogenesis of type 2 diabetes and metabolism. Curr Opin Clin Nutr Metab Care. 2007;10:420-426. 
18. Qi L, Hu FB, Hu G. Genes, environment, and interactions in prevention of type 2 diabetes: a focus on physical activity and lifestyle changes. Curr Mol Med. 2008;8:519-532.

19. Uusitupa M, Peltonen M, Lindstrom J, et al. Ten-year mortality and cardiovascular morbidity in the Finnish Diabetes Prevention Study secondary analysis of the randomized trial. PloS One. 2009;4:e5656.

20. Brown LC, Majumdar SR, Johnson JA. Type of antidepressant therapy and risk of type 2 diabetes in people with depression. Diabetes Res Clin Pract. 2008;79:61-67.

21. Andersohn F, Schade R, Suissa S, Garbe E. Long-term use of antidepressants for depressive disorders and the risk of diabetes mellitus. Am J Psychiatry. 2009;166:591-598.

22. Kivimaki M, Hamer M, Batty GD, et al. Antidepressant medication use, weight gain, and risk of type 2 diabetes: a population-based study. Diabetes Care. 2010;33:2611-2616.

23. Kivimaki M, Batty GD. Antidepressant drug use and future diabetes risk. Diabetologia. 2012;55:10-12.

24. Sharif A, Baboolal K. Risk factors for new-onset diabetes after kidney transplantation. Nat Rev Nephrol. 2010;6:415-423.

25. Lane JT, Dagogo-Jack S. Approach to the patient with new-onset diabetes after transplant (NODAT). J Clin Endocrinol Metab. 2011;96:3289-3297.

26. Hales CN, Barker DJ. The thrifty phenotype hypothesis. Br Med Bull. 2001;60:5-20.

27. Pinney SE, Simmons RA. Epigenetic mechanisms in the development of type 2 diabetes. Trends Endocrinol Metabol. 2010;21:223-229.

28. Lehnen H, Zechner U, Haaf T. Epigenetics of gestational diabetes mellitus and offspring health: the time for action is in early stages of life. Mol Hum Reprod. 2013;19:415-422.

29. Prasai MJ, Mughal RS, Wheatcroft SB, Kearney MT, Grant PJ, Scott EM. Diurnal variation in vascular and metabolic function in diet-induced obesity: divergence of insulin resistance and loss of clock rhythm. Diabetes. 2013;62:1981-1989.

30. Richards J, Gumz ML. Mechanism of the circadian clock in physiology. Am J Physiol. Regulatory, integrative and comparative physiology. 2013;304:R1053-R1064.

31. Shi SQ, Ansari TS, McGuinness OP, Wasserman DH, Johnson CH. Circadian disruption leads to insulin resistance and obesity. Curr Biol. 2013;23:372-381

32. Ryden L, Standl E, Bartnik M, et al. Guidelines on diabetes, prediabetes, and cardiovascular diseases: executive summary. The Task Force on Diabetes and Cardiovascular Diseases of the European Society of Cardiology (ESC) and of the European Association for the Study of Diabetes (EASD). Eur Heart J. 2007;28:88-136.

33. Drozda J Jr, Messer JV, Spertus J, et al. ACCF/AHA/AMA-PCPI 2011 performance measures for adults with coronary artery disease and hypertension: a report of the American College of Cardiology Foundation/American Heart Association Task Force on Performance Measures and the American Medical Association-Physician Consortium for Performance Improvement. J Am Coll Cardiol. 2011;58: 316-336.

34. Tirosh A, Shai I, Tekes-Manova D, et al. Normal fasting plasma glucose levels and type 2 diabetes in young men. $N$ Engl J Med. 2005;353: 1454-1462.

35. Dankner R, Abdul-Ghani MA, Gerber Y, Chetrit A, Wainstein J, Raz I. Predicting the 20-year diabetes incidence rate. Diabetes. 2007;23: 551-558.

36. Godsland IF, Jeffs JA, Johnston DG. Loss of beta cell function as fasting glucose increases in the non-diabetic range. Diabetologia. 2004;47:1157-1166.

37. Ziegler D, Rathmann W, Dickhaus T, Meisinger C, Mielck A. Neuropathic pain in diabetes, prediabetes and normal glucose tolerance: the MONICA/KORA Augsburg Surveys S2 and S3. Pain Med. 2009;10: 393-400.

38. Nichols GA, Arondekar B, Herman WH. Complications of dysglycemia and medical costs associated with nondiabetic hyperglycemia. Am J Manag Care. 2008;14:791-798.
39. Triggle CR. The early effects of elevated glucose on endothelial function as a target in the treatment of type 2 diabetes. Timely Top Med Cardiovasc Dis. 2008;12:E3.

40. Shaw J. Diagnosis of prediabetes. Med Clin North Am. 2011;95: 341-352, viii.

41. Qiao Q, Jousilahti P, Eriksson J, Tuomilehto J. Predictive properties of impaired glucose tolerance for cardiovascular risk are not explained by the development of overt diabetes during follow-up. Diabetes Care. 2003;26:2910-2914.

42. Abdul-Ghani MA, Tripathy D, DeFronzo RA. Contributions of betacell dysfunction and insulin resistance to the pathogenesis of impaired glucose tolerance and impaired fasting glucose. Diabetes Care. 2006;29: 1130-1139.

43. DeFronzo RA, Abdul-Ghani MA. Preservation of beta-cell function: the key to diabetes prevention. J Clin Endocrinol Metab. 2011;96: 2354-2366.

44. Stancakova A, Javorsky M, Kuulasmaa T, Haffner SM, Kuusisto J, Laakso M. Changes in insulin sensitivity and insulin release in relation to glycemia and glucose tolerance in 6,414 Finnish men. Diabetes. 2009;58:1212-1221.

45. Ferrannini E, Gastaldelli A, Iozzo P. Pathophysiology of prediabetes. Med Clin North Am. 2011;95:327-339, vii-viii.

46. Defronzo RA. Banting Lecture. From the triumvirate to the ominous octet: a new paradigm for the treatment of type 2 diabetes mellitus. Diabetes. 2009;58:773-795.

47. Kanat M, Mari A, Norton L, et al. Distinct beta-cell defects in impaired fasting glucose and impaired glucose tolerance. Diabetes. 2012;61:447-453.

48. Festa A, Williams K, Hanley AJ, Haffner SM. Beta-cell dysfunction in subjects with impaired glucose tolerance and early type 2 diabetes: comparison of surrogate markers with first-phase insulin secretion from an intravenous glucose tolerance test. Diabetes. 2008;57: $1638-1644$

49. DECODE Study Group, the European Diabetes Epidemiology Group. Glucose tolerance and cardiovascular mortality: comparison of fasting and 2-hour diagnostic criteria. Arch Intern Med. 2001;161: $397-405$.

50. Hoerger TJ, Hicks KA, Sorensen SW, et al. Cost-effectiveness of screening for pre-diabetes among overweight and obese US adults. Diabetes Care. 2007;30:2874-2879.

51. Wang-Sattler R, Yu Z, Herder C, et al. Novel biomarkers for pre-diabetes identified by metabolomics. Mol Sys Biology. 2012;8:615.

52. Kolberg J, Wagenknecht L, Rowe MW. Performance of a multi-marker diabetes risk score on the Insulin Resistance Atherosclerosis Study (IRAS), a multi-ethnic US cohort. 6th World Congress on Prevention of Diabetes and its Complications, April 8-11, Dresden, German, 2010

53. McKenna M, Lyssenko V, Rowe M. Validation of the Diabetes Risk Score, a Multi-Marker Panel that Assesses the Risk of Type 2 Diabetes: Combined Results of the Inter99 and Botnia Studies. 69th Scientific Sessions of the American Diabetes Association (ADA), June 5-9, New Orleans, Louisiana, 2009.

54. Feskens EJ, Virtanen SM, Rasanen L, et al. Dietary factors determining diabetes and impaired glucose tolerance. A 20-year follow-up of the Finnish and Dutch cohorts of the Seven Countries Study. Diabetes Care. 1995;18:1104-1112.

55. Tuomilehto J, Lindstrom J, Eriksson JG, et al. Prevention of type 2 diabetes mellitus by changes in lifestyle among subjects with impaired glucose tolerance. $N$ Engl J Med. 2001;344:1343-1350.

56. Carr SM, Lhussier M, Forster N, et al. An evidence synthesis of qualitative and quantitative research on component intervention techniques, effectiveness, cost-effectiveness, equity and acceptability of different versions of health-related lifestyle advisor role in improving health. Health Technol Assess. 2011;15:iii-iv, 1-284.

57. Simmons RK, Unwin N, Griffin SJ. International Diabetes Federation: an update of the evidence concerning the prevention of type 2 diabetes. Diabetes Res Clin Pract. 2010;87:143-149. 
58. World Health Organization [homepage on the Internet]. 2008-2013 Action plan for the global strategy for the prevention and control of noncommunicable diseases. Geneva: WHO Press; 2008. Available from: http://www.who.int/nmh/publications/9789241597418/en. Accessed December 12, 2013.

59. Saha S, Gerdtham UG, Johansson P. Economic evaluation of lifestyle interventions for preventing diabetes and cardiovascular diseases. Int J Environ Res Public Health. 2010;7:3150-3195.

60. Radl K, Ianuale C, Boccia S. A systematic review of the cost-effectiveness of lifestyle modification as primary prevention intervention for type 2 diabetes mellitus. Epidemiol Biostat Public Health. 2013;10:e88461-e8846-8

61. Pan XR, Li GW, Hu YH, et al. Effects of diet and exercise in preventing NIDDM in people with impaired glucose tolerance. The Da Qing IGT and Diabetes Study. Diabetes Care. 1997;20:537-544.

62. Li G, Zhang P, Wang J, et al. The long-term effect of lifestyle interventions to prevent diabetes in the China Da Qing Diabetes Prevention Study: a 20-year follow-up study. Lancet. 2008;371:1783-1789.

63. Ramachandran A, Snehalatha C, Mary S, Mukesh B, Bhaskar AD, Vijay V. The Indian Diabetes Prevention Programme shows that lifestyle modification and metformin prevent type 2 diabetes in Asian Indian subjects with impaired glucose tolerance (IDPP-1). Diabetologia. 2006:49:289-297.

64. Kosaka K, Noda M, Kuzuya T. Prevention of type 2 diabetes by lifestyle intervention: a Japanese trial in IGT males. Diabetes Res Clin Pract. 2005;67:152-162.

65. Lindstrom J, Ilanne-Parikka P, Peltonen M, et al. Sustained reduction in the incidence of type 2 diabetes by lifestyle intervention: follow-up of the Finnish Diabetes Prevention Study. Lancet. 2006;368 1673-1679.

66. Knowler WC, Barrett-Connor E, Fowler SE, et al. Reduction in the incidence of type 2 diabetes with lifestyle intervention or metformin. N Engl J Med. 2002;346:393-403.

67. Crandall JP, Knowler WC, Kahn SE, et al. The prevention of type 2 diabetes. Nat Clin Pract Endocrinol Metab. 2008;4:382-393.

68. Laaksonen DE, Lindstrom J, Lakka TA, et al. Physical activity in the prevention of type 2 diabetes: the Finnish diabetes prevention study. Diabetes. 2005;54:158-165.

69. Salas-Salvado J, Martinez-Gonzalez MA, Bullo M, Ros E. The role of diet in the prevention of type 2 diabetes. Nutr Metabol Cardiovasc Dis. 2011;21 Suppl 2:B32-B48.

70. Dansinger ML, Tatsioni A, Wong JB, Chung M, Balk EM. Metaanalysis: the effect of dietary counseling for weight loss. Ann Intern Med. 2007;147:41-50.

71. Schwarz PE, Greaves CJ, Lindström J, Yates T, Davies MJ. Nonpharmacological interventions for the prevention of type 2 diabetes mellitus. Nat Rev Endocrinol. 2012;8:363-373.

72. Oldridge NB. Economic burden of physical inactivity: healthcare costs associated with cardiovascular disease. Eur J Cardiovasc Prev Rehabil. 2008;15:130-139.

73. Blair SN. Physical inactivity: the biggest public health problem of the 21st century. Br J Sports Med. 2009;43:1-2.

74. Yates T, Davies M, Gorely T, Bull F, Khunti K. Effectiveness of a pragmatic education program designed to promote walking activity in individuals with impaired glucose tolerance: a randomized controlled trial. Diabetes Care. 2009;32:1404-1410.

75. Telford RD. Low physical activity and obesity: causes of chronic disease or simply predictors? Med Sci Sports Exerc. 2007;39. 1233-1240.

76. World Health Organization [homepage on the Internet]. Global recommendations on physical activity for health. Geneva: WHO Press, 2010. Available from: http://www.who.int/dietphysicalactivity/ factsheet_recommendations/en. Accessed December 12, 2013.

77. Knowler WC, Fowler SE, Hamman RF, et al. Diabetes Prevention Program Research Group. 10-year follow-up of diabetes incidence and weight loss in the Diabetes Prevention Program Outcomes Study. Lancet. 2009;374:1677-1686.
78. Tuomilehto J, Schwarz P, Lindstrom J. Long-term benefits from lifestyle interventions for type 2 diabetes prevention. Diabetes Care. 2011;34(Suppl 2):S210-S214.

79. Altman DG. Sustaining interventions in community systems: on the relationship between researchers and communities. Health Psychol. 1995; 14:526-536.

80. O'Toole TP, Aaron KF, Chin MH, Horowitz C, Tyson F. Community-based participatory research: opportunities, challenges, and the need for a common language. J Gen Intern Med. 2003;18: 592-594.

81. Schwarz PE, Reddy P, Greaves C, Dunbar J, Schwarz J, editors. Diabetes Prevention in Practice. Dresden, Germany: TUMAINI Institute for Prevention Management; 2010.

82. Finnish Diabetes Association. Programme for the Prevention of Type 2 Diabetes in Finland, 2003-2010. Tampere, Finland: Finnish Diabetes Association; 2003. Available from: http://www.diabetes.fi/ files/1108/Programme_for_the_Prevention_of_Type_2_Diabetes_in_ Finland_2003-2010.pdf. Accessed August 2, 2013.

83. Saaristo T, Moilanen L, Korpi-Hyövälti E, et al. Lifestyle intervention for prevention of type 2 diabetes in primary health care: one-year follow-up of the Finnish National Diabetes Prevention Program (FIN-D2D). Diabetes Care. 2010;33:2146-2151.

84. Schwarz PE, Lindström J, Kissimova-Scarbeck K, et al. The European perspective of type 2 diabetes prevention: diabetes in Europe - prevention using lifestyle, physical activity and nutritional intervention (DE-PLAN) project. Exp Clin Endocrinol Diabetes. 2008;116:167-172.

85. Vermunt PWA, Milder IEJ, Wiellard F, Vries JHM, van Oers HAM, Westert GP. Lifestyle counseling for type 2 diabetes risk reduction in Dutch primary care. Results of the APHRODITE study after 0.5 and 1.5 years. Diabetes Care. 2011;24:1919-1925.

86. Rosal MC, Benjamin EM, Pekow PS, Lemon SC, von Goeler D. Opportunities and challenges for diabetes prevention at two community health centers. Diabetes Care. 2008;31:247-254.

87. Paulweber B, Valensi P, Lindström J, et al. A European evidence-based guideline for the prevention of type 2 diabetes. Horm Metab Res. 2010;42:S3-S36.

88. Lindström J, Neumann A, Sheppard KE, et al. Take action to prevent diabetes: the IMAGE toolkit for the prevention of type 2 diabetes in Europe. Horm Metab Res. 2010;42:S37-S55.

89. Pajunen P, Landgraf R, Muylle F, et al. Quality indicators for the prevention of type 2 diabetes in Europe: IMAGE. Horm Metab Res. 2010;42:S56-S63.

90. Uusitupa M, Tuomilehto J, Puska P. Are we really active in the prevention of obesity and type 2 diabetes at the community level? Nutr Metab Cardiovasc Dis. 2011;21:380-389.

91. Absetz P, Oldenburg B, Hankonen N, et al. Type 2 diabetes prevention in the real world: three-year results of the GOAL Lifestyle Implementation Trial. Diabetes Care. 2009;32:1418-1420.

92. Ackermann RT, Finch EA, Brizendine E, Zhou H, Marrero DG. Translating the Diabetes Prevention Program into the community: the DEPLOY pilot study. Am J Prev Med. 2008;35:357-363.

93. Kulzer B, Hermanns N, Gorges D, Schwarz P, Haak T. Prevention of diabetes self-management program (PREDIAS): effects on weight, metabolic risk factors, and behavioral outcomes. Diabetes Care. 2009;32:1143-1146.

94. Laatikainen T, Dunbar JA, Chapman A, et al. Prevention of type 2 diabetes by lifestyle intervention in an Australian primary health care setting: Greater Green Triangle (GGT) Diabetes Prevention Project. BMC Public Health. 2007;7:249.

95. Makrilakis K, Liatis S, Grammatikou S, Perrea D, Katsilambros N. Implementation and effectiveness of the first community lifestyle intervention programme to prevent type 2 diabetes in Greece: the DEPLAN study. Diabet Med. 2010;27:459-465.

96. Penn L, Moffatt SM, White M. Participants' perspective on maintaining behavior change: a qualitative study within the European Diabetes Prevention Study. BMC Public Health. 2008;8:235. 
97. Kronsbein P, Fischer MR, Tolks D, et al. IMAGE: Development of a European curriculum for the training of prevention managers. $\mathrm{Br} J$ Diabetes Vasc Dis. 2011;11:163-167.

98. Crist JD, Escandon-Dominguez S. Identifying and recruiting Mexican American partners and sustaining community partnerships. JTranscult Nurs. 2003;14:266-271.

99. Foster J, Stanek K. Cross-cultural considerations in the conduct of community-based participatory research. Fam Community Health. 2007;30:42-49.

100. Lasker RD, Weiss ES. Creating partnership synergy: the critical role of community stakeholders. J Health Hum Serv Adm. 2003;26: 119-139.

101. Caldwell CH, Zimmerman MA, Isichei PA. Forging collaborative partnerships to enhance family health: an assessment of strengths and challenges in conducting community-based research. J Public Health Manag Pract. 2001;7:1-9.

102. Bryant CA, Brown KR, McDermott RJ, et al. Community-based prevention marketing: organizing a community for health behavior intervention. Health Promot Pract. 2007;8:154-163.

103. Christopher S, Watts V, McCormick AK, Young S. Building and maintaining trust in a community-based participatory research partnership. Am J Public Health. 2008;98:1398-1406.

104. Cotter JJ, Welleford EA, Vesley-Massey K, Thurston MO. Collaborative community-based research and innovation. Fam Community Health. 2003;26:329-337.

105. Kaplan SA, Calman NS, Golub M, Ruddock C, Billings J. Fostering organizational change through a community-based initiative. Health Promot Pract. 2006;7:181S-190S.

106. Katz DL. Representing your community in community-based participatory research: differences made and measured. Prev Chronic Dis. 2004; 1 :A12.

107. Kelly KJ, Van Vlaenderen H. Dynamics of participation in a community health project. Soc Sci Med. 1996;42:1235-1246.

108. Kelly PJ. Practical suggestions for community interventions using participatory action research. Public Health Nurs. 2005;22:65-73.

109. Kone A, Sullivan M, Senturia KD, Chrisman NJ, Ciske SJ, Krieger JW. Improving collaboration between researchers and communities. Public Health Rep. 2000;115:243-248.

110. Lantz PM, Viruell-Fuentes E, Israel BA, Softley D, Guzman R. Can communities and academia work together on public health research? Evaluation results from a community-based participatory research partnership in Detroit. J Urban Health. 2001;78:495-507.

111. Lasker RD, Weiss ES. Broadening participation in community problem solving: a multidisciplinary model to support collaborative practice and research. J Urban Health. 2003;80:14-47; discussion 48-60.

112. Minkler M. Community-based research partnerships: challenges and opportunities. J Urban Health. 2005;82:ii3-ii12.

113. Nelson G, Pancer SM, Hayward K, Kelly R. Partnerships and participation of community residents in health promotion and prevention: experiences of the highfield community enrichment project (better beginnings, better futures). J Health Psychol. 2004;9:213-227.

114. Pinto RM, McKay MM, Escobar C. "You've gotta know the community": minority women make recommendations about community-focused health research. Wom Health. 2008;47:83-104.

115. Shelton D. Establishing the public's trust through community-based participatory research: a case example to improve health care for a rural Hispanic community. Annu Rev Nurs Res. 2008;26:237-259.

116. Viswanathan M, Ammerman A, Eng E, et al. Community-based participatory research: assessing the evidence. Evid Rep Technol Assess (Summ). 2004;(99):1-8.

117. Dehaven MJ, Chen L. Teaching medical students research while reaching the underserved. Fam Med. 2005;37:315-317.

118. Carline JD, Patterson DG. Characteristics of health professions schools, public school systems, and community-based organizations in successful partnerships to increase the numbers of underrepresented minority students entering health professions education. Acad Med. 2003;78:467-482.
119. Wallerstein NB, Duran B. Using community-based participatory research to address health disparities. Health Prom Pract. 2006; 7: 312-323.

120. Wandersman A. Community science: bridging the gap between science and practice with community-centered models. Am J Community Psychol. 2003;31:227-242.

121. Wisdom K. Strategies for community participation in diabetes prevention: a Detroit experience. Ethn Dis. 2003;13:S3-63-66.

122. Zambrana RE. The role of Latino/Hispanic communities in health services research: strategies for a meaningful partnership. J Med Syst. 1996;20:317-328.

123. Horowitz CR, Goldfinger JZ, Muller SE, et al. A model for using community-based participatory research to address the diabetes epidemic in East Harlem. Mt Sinai J Med. 2008;75:13-21.

124. Laverack G, Labonte R. A planning framework for community empowerment goals within health promotion. Health Policy Plan. 2000;15:255-262.

125. Matheson A, Howden-Chapman P, Dew K. Engaging communities to reduce health inequalities: why partnership? Soc Policy $J N Z$. 2005;26:1

126. Zhou G, Myers R, Li Y, et al. Role of AMP-activated protein kinase in mechanism of metformin action. J Clin Invest. 2001;108: 1167-1174.

127. Salpeter SR, Buckley NS, Kahn JA, Salpeter EE. Meta-analysis: metformin treatment in persons at risk for diabetes mellitus. Am J Med. 2008;121:149-157. e2.

128. Barnea M, Haviv L, Gutman R, Chapnik N, Madar Z, Froy O. Metformin affects the circadian clock and metabolic rhythms in a tissue-specific manner. Biochim Biophys Acta. 2012;1822: 1796-1806.

129. Chiasson JL, Josse RG, Leiter LA, et al. The effect of acarbose on insulin sensitivity in subjects with impaired glucose tolerance. Diabetes Care. 1996;19:1190-1193.

130. Chiasson JL, Josse RG, Gomis R, Hanefeld M, Karasik A, Laakso M. Acarbose for prevention of type 2 diabetes mellitus: the STOP-NIDDM randomised trial. Lancet. 2002;359:2072-2077.

131. Chiasson JL, Josse RG, Gomis R, Hanefeld M, Karasik A, Laakso M. Acarbose treatment and the risk of cardiovascular disease and hypertension in patients with impaired glucose tolerance: the STOP-NIDDM trial. JAMA. 2003;290:486-494.

132. Chiasson JL, Josse RG, Gomis R, Hanefeld M, Karasik A, Laakso M. Acarbose for the prevention of Type 2 diabetes, hypertension and cardiovascular disease in subjects with impaired glucose tolerance: facts and interpretations concerning the critical analysis of the STOPNIDDM Trial data. Diabetologia. 2004;47:969-975; discussion 976-977.

133. Unger RH, Zhou YT. Lipotoxicity of beta-cells in obesity and in other causes of fatty acid spillover. Diabetes. 2001;50 Suppl 1: S118-S121.

134. Higa M, Zhou YT, Ravazzola M, Baetens D, Orci L, Unger RH. Troglitazone prevents mitochondrial alterations, beta cell destruction, and diabetes in obese prediabetic rats. Proc Natl Acad Sci U S A. 1999;96:11513-11518.

135. Buchanan TA, Xiang AH, Peters RK, et al. Preservation of pancreatic beta-cell function and prevention of type 2 diabetes by pharmacological treatment of insulin resistance in high-risk Hispanic women. Diabetes. 2002;51:2796-2803.

136. Xiang AH, Peters RK, Kjos SL, et al. Effect of pioglitazone on pancreatic beta-cell function and diabetes risk in Hispanic women with prior gestational diabetes. Diabetes. 2006;55:517-522.

137. Defronzo RA, Banerji M, Bray GA, et al. Actos Now for the Prevention of Diabetes (ACT NOW) study. BMC Endocr Disord. 2009;9:17.

138. DeFronzo RA, Tripathy D, Schwenke DC, et al. Pioglitazone for diabetes prevention in impaired glucose tolerance. $N$ Engl J Med. 2011;364:1104-1115.

139. Gerstein HC, Yusuf S, Bosch J, et al. Effect of rosiglitazone on the frequency of diabetes in patients with impaired glucose tolerance or impaired fasting glucose: a randomised controlled trial. Lancet. 2006;368:1096-1105. 
140. Zinman B, Harris SB, Neuman J, et al. Low-dose combination therapy with rosiglitazone and metformin to prevent type 2 diabetes mellitus (CANOE trial): a double-blind randomised controlled study. Lancet. 2010;376:103-111.

141. Home PD, Pocock SJ, Beck-Nielsen H, et al. Rosiglitazone evaluated for cardiovascular outcomes in oral agent combination therapy for type 2 diabetes (RECORD): a multicentre, randomised, open-label trial. Lancet. 2009;373:2125-2135.

142. Torgerson JS, Hauptman J, Boldrin MN, Sjostrom L. XENical in the prevention of diabetes in obese subjects (XENDOS) study: a randomized study of orlistat as an adjunct to lifestyle changes for the prevention of type 2 diabetes in obese patients. Diabetes Care. 2004;27:155-161.

143. Gerstein HC, Bosch J, Dagenais GR, et al. Basal insulin and cardiovascular and other outcomes in dysglycemia. NEngl J Med. 2012;367: 319-328.

144. Perreault L, Pan Q, Mather KJ, Watson KE, Hamman RF, Kahn SE. Effect of regression from prediabetes to normal glucose regulation on long-term reduction in diabetes risk: results from the Diabetes Prevention Program Outcomes Study. Lancet. 2012;379:2243-2251.

145. Marina AL, Utzschneider KM, Wright LA, Montgomery BK, Marcovina SM, Kahn SE. Colesevelam improves oral but not intravenous glucose tolerance by a mechanism independent of insulin sensitivity and beta-cell function. Diabetes Care. 2012;35 1119-1125.

146. Handelsman Y, Goldberg RB, Garvey WT, et al. Colesevelam hydrochloride to treat hypercholesterolemia and improve glycemia in prediabetes: a randomized, prospective study. Endocr Pract. 2010;16: 617-628.

147. Rosenstock J, Hernandez-Triana E, Handelsman Y, Misir S, Jones MR. Clinical effects of colesevelam in Hispanic subjects with primary hyperlipidemia and prediabetes. Postgrad Med. 2012;124:14-20.

148. Rosenstock J, Zinman B. Dipeptidyl peptidase-4 inhibitors and the management of type 2 diabetes mellitus. Curr Opin Endocrinol Diabetes Obes. 2007;14:98-107.

149. Rosenstock J, Baron MA, Dejager S, Mills D, Schweizer A. Comparison of vildagliptin and rosiglitazone monotherapy in patients with type 2 diabetes: a 24-week, double-blind, randomized trial. Diabetes Care. 2007;30:217-223.

150. Schweizer A, Couturier A, Foley JE, Dejager S. Comparison between vildagliptin and metformin to sustain reductions in $\mathrm{HbA}(1 \mathrm{c})$ over 1 year in drug-naive patients with Type 2 diabetes. Diabetic Med. 2007;24:955-961.

151. Balas B, Baig MR, Watson C, et al. The dipeptidyl peptidase IV inhibitor vildagliptin suppresses endogenous glucose production and enhances islet function after single-dose administration in type 2 diabetic patients. J Clin Endocrinol Metab. 2007;92:1249-1255.

152. Vella A, Bock G, Giesler PD, et al. Effects of dipeptidyl peptidase-4 inhibition on gastrointestinal function, meal appearance, and glucose metabolism in type 2 diabetes. Diabetes. 2007;56:1475-1480.

153. Rosenstock J, Foley JE, Rendell M, et al. Effects of the dipeptidyl peptidase-IV inhibitor vildagliptin on incretin hormones, islet function, and postprandial glycemia in subjects with impaired glucose tolerance. Diabetes Care. 2008;31:30-35.

154. Zander M, Madsbad S, Madsen JL, Holst JJ. Effect of 6-week course of glucagon-like peptide 1 on glycaemic control, insulin sensitivity, and beta-cell function in type 2 diabetes: a parallel-group study. Lancet. 2002;359:824-830

155. Astrup A, Rossner S, Van Gaal L, et al. Effects of liraglutide in the treatment of obesity: a randomised, double-blind, placebo-controlled study. Lancet. 2009;374:1606-1616.

156. Flint A, Kapitza C, Hindsberger C, Zdravkovic M. The once-daily human glucagon-like peptide-1 (GLP-1) analog liraglutide improves postprandial glucose levels in type 2 diabetes patients. Adv Ther 2011;28:213-226.

157. Guo N, Sun J, Chen H, Zhang H, Zhang Z, Cai D. Liraglutide prevents diabetes progression in prediabetic OLETF rats. Endocr J. 2013;60: 15-28.
158. Rosenstock J, Klaff LJ, Schwartz S, et al. Effects of exenatide and lifestyle modification on body weight and glucose tolerance in obese subjects with and without pre-diabetes. Diabetes Care. 2010;33: 1173-1175.

159. Astrup A, Carraro R, Finer N, et al. Safety, tolerability and sustained weight loss over 2 years with the once-daily human GLP-1 analog, liraglutide. Int J Obes. 2012;36:843-854.

160. Yale University. The Effects of Exenatide on Post-Meal Sugar Peaks and Vascular Health in Obese/Pre-Diabetic Young Adults. Available from: http:/clinicaltrials.gov/show/NCT00845559. NLM identifier: NCT00845559. Accessed December 20, 2013.

161. Carlsson LM, Peltonen M, Ahlin S, et al. Bariatric surgery and prevention of type 2 diabetes in Swedish obese subjects. $N$ Engl J Med. 2012;367:695-704.

162. de la Cruz-Munoz N, Messiah SE, Arheart KL, Lopez-Mitnik G, Lipshultz SE, Livingstone A. Bariatric surgery significantly decreases the prevalence of type 2 diabetes mellitus and pre-diabetes among morbidly obese multiethnic adults: long-term results. J Am Coll Surg 2011;212:505-511; discussion 512-513.

163. Sjoholm K, Anveden A, Peltonen M, et al. Evaluation of current eligibility criteria for bariatric surgery: diabetes prevention and risk factor changes in the Swedish obese subjects (SOS) study. Diabetes Care. 2013;36:1335-1340.

164. Leccesi L, Panunzi S, De Gaetano A, et al. Effects of transoral gastroplasty on glucose homeostasis in obese subjects. J Clin Endocrinol Metab. 2013;98:1901-1910.

165. Luo S, Luo J, Cincotta AH. Association of the antidiabetic effects of bromocriptine with a shift in the daily rhythm of monoamine metabolism within the suprachiasmatic nuclei of the Syrian hamster. Chronobiol Int. 2000;17:155-172.

166. Erminio P. Ergot Compounds and Brain Function: Neuroendocrine and Neuropsychiatrics Aspects. In: Goldstein M, editor. Adv Biochem Psychopharmacol. New York: Raven; 1980:41-62.

167. Luo S, Liang Y, Cincotta AH. Intracerebroventricular administration of bromocriptine ameliorates the insulin-resistant/glucose-intolerant state in hamsters. Neuroendocrinology. 1999;69:160-166.

168. Cincotta AH, Meier AH, Southern LL. Bromocriptine alters hormone rhythms and lipid metabolism in swine. Ann Nutr Metabol. 1989;33: 305-314.

169. Cincotta AH, Schiller BC, Meier AH. Bromocriptine inhibits the seasonally occurring obesity, hyperinsulinemia, insulin resistance, and impaired glucose tolerance in the Syrian hamster, Mesocricetus auratus. Metabolism. 1991;40:639-644.

170. Cincotta AH, Meier AH, Cincotta M Jr. Bromocriptine improves glycaemic control and serum lipid profile in obese Type 2 diabetic subjects: a new approach in the treatment of diabetes. Expert Opin Invest Drugs. 1999;8:1683-1707.

171. Cincotta AH, MacEachern TA, Meier AH. Bromocriptine redirects metabolism and prevents seasonal onset of obese hyperinsulinemic state in Syrian hamsters. Am J Physiol. 1993;264:E285-E293.

172. Gadde KM, Allison DB, Ryan DH, et al. Effects of low-dose, controlled-release, phentermine plus topiramate combination on weight and associated comorbidities in overweight and obese adults (CONQUER): a randomised, placebo-controlled, phase 3 trial. Lancet. 2011;377:1341-1352.

173. Garvey WT, Ryan DH, Look M, et al. Two-year sustained weight loss and metabolic benefits with controlled-release phentermine/ topiramate in obese and overweight adults (SEQUEL): a randomized, placebo-controlled, phase 3 extension study. Am J Clin Nutr. 2012;95:297-308.

174. Garvey WT, Ryan DH, Henry R, et al. Prevention of type 2 diabetes in subjects with prediabetes and metabolic syndrome treated with phentermine and topiramate extended-release. Diabetes Care. Epub October 8, 2013

175. O’Neil PM, Smith SR, Weissman NJ, et al. Randomized placebocontrolled clinical trial of lorcaserin for weight loss in type 2 diabetes mellitus: the BLOOM-DM study. Obesity (Silver Spring). 2012;20:1426-1436. 
176. Smith SR, Weissman NJ, Anderson CM, et al. Multicenter, placebocontrolled trial of lorcaserin for weight management. $N$ Engl J Med. 2010;363:245-256.
177. Fidler MC, Sanchez M, Raether B, et al. A one-year randomized trial of lorcaserin for weight loss in obese and overweight adults: the BLOSSOM trial. J Clin Endocrinol Metab. 2011;96:3067-3077.

\section{Publish your work in this journal}

Therapeutics and Clinical Risk Management is an international, peerreviewed journal of clinical therapeutics and risk management, focusing on concise rapid reporting of clinical studies in all therapeutic areas, outcomes, safety, and programs for the effective, safe, and sustained use of medicines. This journal is indexed on PubMed Central, CAS,
EMBase, Scopus and the Elsevier Bibliographic databases. The manuscript management system is completely online and includes a very quick and fair peer-review system, which is all easy to use. Visit http://www.dovepress.com/testimonials.php to read real quotes from published authors.

Submit your manuscript here: http://www.dovepress.com/therapeutics-and-clinical-risk-management-journal 